\title{
Туннельный точечный контакт в терагерцовом поле
}

3.Д. Квон ${ }^{1,2)}$, О.А. Ткаченко ${ }^{1)}$, В.А. Ткаченко ${ }^{1,2)}$, Д.Г.Бакшеев ${ }^{2)}$, А.С. Ярошевич ${ }^{1)}$, Е.Е.Родякина ${ }^{1,2)}$, A.B. Латышев ${ }^{1,2)}$, M. Otteneder ${ }^{3)}$, S.D. Ganichev ${ }^{3)}$

${ }^{1}$ Институт физики полупроводников им. А.В.Ржсанова СО РАН, Новосибирск, 630090, пр. Ак. Лаврентьева, 13

тел:+7 (383) 333-10-80, факс:+7 (383) 333-10-80, эл. nочта: vtkach@isp.nsc.ru

${ }^{2}$ Новосибирский государственный университет, Новосибирск, 630090,

${ }^{3}$ Terahertz Center, University of Regensburg, 93040 Regensburg

DOI 10.34077/RCSP2019-134

Изготовлены квантовые точечные контакты (QPC) в двумерном электронном газе гетероструктур GaAs/AlGaAs и выполнены измерения отклика туннельного кондактанса устройств на терагерцовое облучение [1] (рис.1,2). Поляризационные измерения (рис.2) показывают, что отклик зависит только от компоненты внешнего ВЧ поля Е( $\omega)$, которая направлена вдоль тока в узком месте. Это позволяет свести объяснение к численному решению одномерной задачи о фотон-ассистированном прохождении через барьер $\mathrm{U}(\mathrm{x}, \mathrm{t}) \approx[\mathrm{V}+\mathrm{A} \cos (\omega \mathrm{t})] / \mathrm{ch}^{2}(\mathrm{x} / \mathrm{W})$. Для такого барьера давно предсказаны два эффекта. Первый из них - гигантский рост коэффициента прохождения $\mathrm{D}$ частицы с начальной энергией $\mathrm{E}<\mathrm{V}$ при низких и умеренных частотах [2-4] (вплоть до 0.7 ТГц для туннельного контакта с $\mathrm{W} \approx 100$ нм в двумерном электронном газе GaAs/AlGaAs структур [4]). Второй эффект - это выход при высоких частотах на значение $\mathrm{D}_{0}(\mathrm{E})$, отвечающее статическому барьеру [2,3]. В работе [1] впервые наблюдались оба эффекта, а результаты моделирования мультифотонного прохождения электрона через туннельный барьер в изготовленных структурах хорошо соответствуют измерениям на частотах f от 0.14 до 1.63 ТГц.

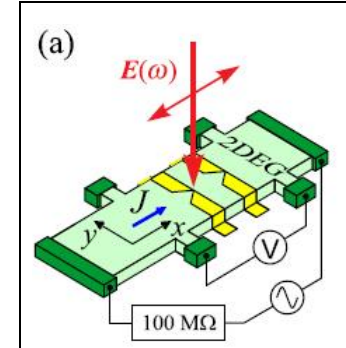

Рис.1. Схема измерений (а) и основной результат (b). На образцах А, В при $\mathrm{f}=0.69$ ТГц наблюдалось гигантское увеличение кондактанса $\mathrm{G}_{\mathrm{ph}}$ по сравнению с темновым $\mathrm{G}_{\mathrm{dark}}$ (точки), а при $\mathrm{f}=1.63$ ТГц оно пропало. Тот же результат (линии в (b) и на вставке) дали формула Ландауэра $\mathrm{G}_{\mathrm{ph}}=\mathrm{G}_{0} \mathrm{D}\left(\mathrm{E}_{\mathrm{F}}\right), \mathrm{G}_{0} \equiv 2 \mathrm{e}^{2} / \mathrm{h}$ и решение нестационарного уравнения Шредингера для найденных реалистических параметров барьера $\mathrm{U}(\mathrm{x}, \mathrm{t}): \mathrm{W} \approx 100$ нм $\mathrm{V} \approx 30$ мэВ, $\mathrm{A} \equiv \mathrm{V}_{0} \sim 1 \div 6$ мэВ
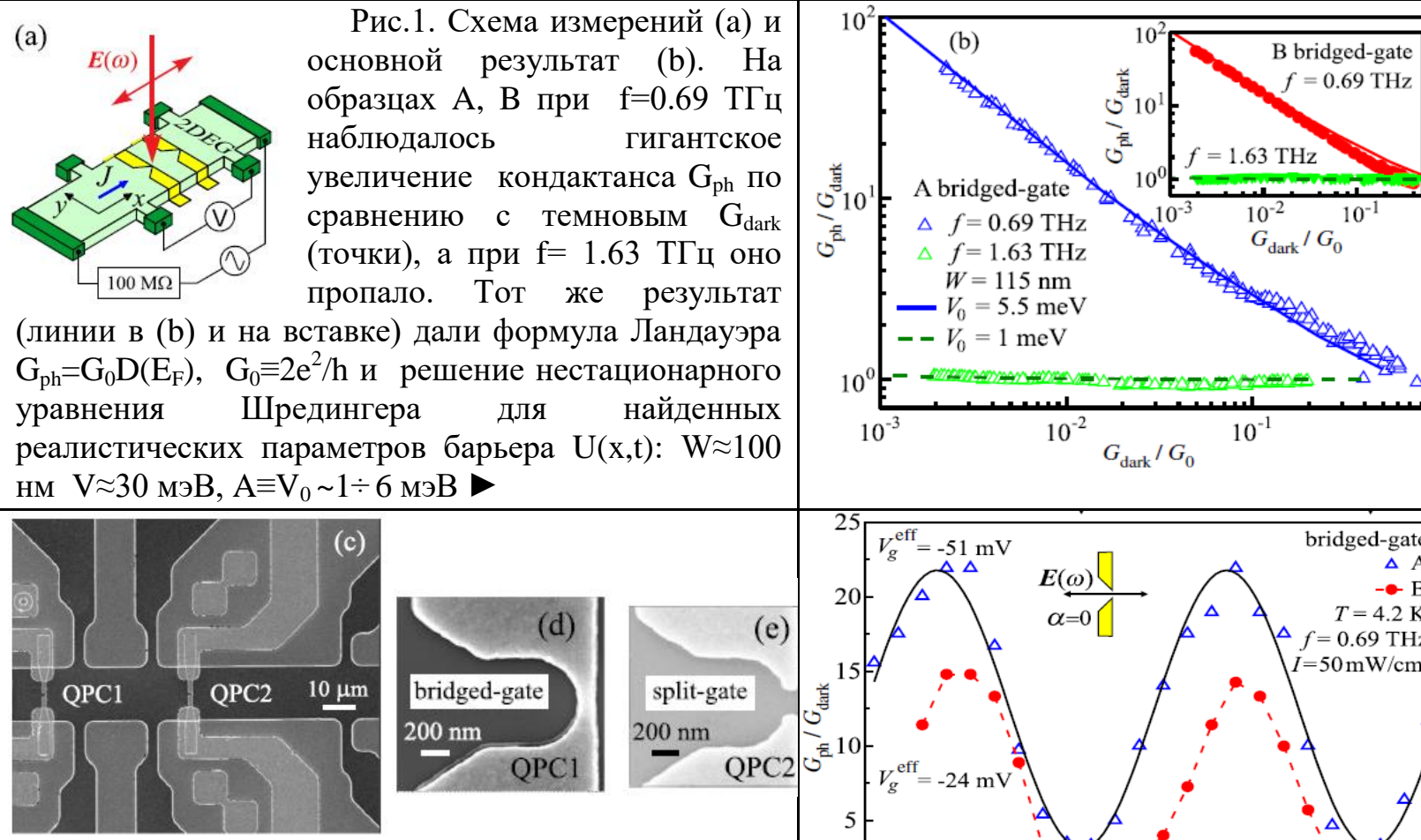

Рис.2. Электронные микрографии устройства $(\mathrm{c}, \mathrm{d}, \mathrm{e})$ и поляризационные измерения $\mathrm{G}_{\mathrm{ph}} / \mathrm{G}_{\mathrm{dark}}$

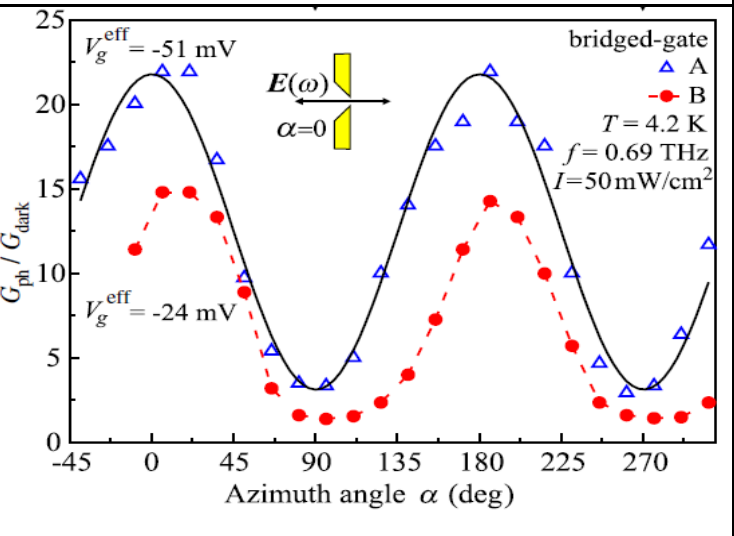

\section{Лumepamypa}

[1] M. Otteneder, Z.D. Kvon, O.A. Tkachenko, V.A. Tkachenko, A.S. Jaroshevich, E.E. Rodyakina, A.V. Latyshev, S.D. Ganichev//Phys. Rev. Applied. 2018. V.10, P. 014015(1-9).

[2] K.Yakubo, S.Feng, Q. Hu // Phys.Rev. B. 1996. V. 54. P. 7987-7995.

[3] J.-Y.Ge, J. Z. H. Zhang//J. Chem. Phys. 1996. V. 105. P. 8628-8632.

[4] O.A. Tkachenko, V.A. Tkachenko, D.G. Baksheyev, H. Nejoh. In: «Quantum coherence and decoherence». Eds. K. Fujikawa,Y.A. Ono. New York, Elsevier. 1996. P. 207-210. 